\title{
A ARGUMENTAÇÃO NUMA PERSPECTIVA MATERIALISTA DO DISCURSO
}

\author{
ARGUMENTATION IN A MATERIALIST \\ PERSPECTIVE OF DISCOURSE
}

\author{
Eduardo Lopes Piris* \\ Universidade Estadual de Santa Cruz, Ilhéus, BA, Brasil
}

Resumo: Neste trabalho, propomos uma reflexão acerca das bases teóricas que fundamentam o estudo da argumentaçã̃o numa perspectiva materialista do discurso. Primeiramente, apresentamos um panorama do relevante lugar que o sujeito passou a ocupar nos estudos sobre argumentação, apoiando-nos em Perelman \& Olbrechts-Tyteca (1996 [1958]), Toulmin (2006 [1958]), Plantin (1996), Maingueneau (2011 [1994]) e Amossy (2007, 2011 [2008], 2013). Depois, concebendo as ideologias como força material que contitui o indivíduo como sujeito, recorremos aos trabalhos de Fuchs \& Pêcheux (2001 [1975]), Pêcheux (2001 [1969]), 1997 [1975]) e Orlandi (1998), para discutir a argumentaccão como parte dos efeitos de sentido entre os sujeitos do discurso. Para tanto, destacamos a interdiscursividade, a antecipaçã̃o e as formaçōes imaginárias como conceitos centrais para o entendimento do mecanismo de argumentação no discurso. Por fim, analisamos o pronunciamento do deputado Mário Covas feito durante a sessão parlamentar de 12 de dezembro de 1968, que antecedeu 0 Al-5.

Palavras-chave: Argumentação; Discurso; Sujeito; Interdiscursividade.

Abstract: This paper proposes an articulation between the Toulmin model of argumentation and the textual-interactive perspective for the analysis of a polemic television interview granted by Fernando Haddad to César Tralli, in the news program SPTV, transmitted by Globo Network, during his campaign for mayor in 2012. This proposal is justified insofar as the Toulmin model allows a schematic formalization of the argumentative structure that supports a critical analysis of the process, whereas the textual-interactive perspective allows comprehending the dynamics of the local production and interpretation of meaning in the conversational text, providing explanatory tools for the construction of the argumentative scheme, which involves the variation in the explicitation of the components of the model and in the configuration of its reciprocal relations. Thus, we could conclude that: (1) the interviewer tends to build the Claim through a question, so that the guest may answer it in form of a Rebuttal, in a process permeated by a face-work dynamics, oriented towards the preservation of his own face, of the interviewer's face and of his party's face, whereby the guest aims to characterize the interviewer's reasoning as fallacious; (2) Warrants and, especially, Backings tend to be implicit; and (3) the argumentative schemes tend to be construed under complex chains.

Keywords: Argumentation; Discourse; Subject; Interdiscussivity.

* Professor doutor do Departamento de Letras e Artes da Universidade Estadual de Santa Cruz - UESC, Ilhéus, BA, Brasil; elpiris@uesc.br 
Linha D'Água (Online), São Paulo, v. 29, n. 2, p. 97-121, dez. 2016

Os homens fazem a bistória, mas não a bistória que eles querem ou acreditam fazer... (Pêcheux parafraseando Marx)

\section{Introdução}

Considerando a tradição de estudos sobre retórica e argumentação e os postulados teóricos da Análise do Discurso, a proposta de trabalhar a argumentação numa perspectiva materialista do discurso nos impõe a reflexão acerca de alguns entraves de ordem epistemológica que têm tornado espinhosa a tarefa de promover uma coerente interface entre discurso e argumentação. Assim, nosso objetivo, neste texto, é discutir alguns princípios teóricos que apontem fundamentos para a análise da argumentação em uma perspectiva discursiva inspirada no trabalho de Michel Pêcheux.

No que toca aos entraves, podemos dizer que uma das grandes fronteiras que separam os estudos da argumentação e os do discurso está nas concepções de língua e de sujeito sustentadas, declara ou não declaradamente, por cada um dos dois lados. Se a discussão teórica acerca desses dois conceitos é cara às teorias do discurso, sobretudo para a Análise do Discurso dita de linha francesa, o mesmo não podemos afirmar acerca dos estudos retóricos e argumentativos, pois sabemos que nunca foi de interesse de Aristóteles ou de Chaïm Perelman, por exemplo, discutir, especificamente, os conceitos de língua e de sujeito, o que torna injusta qualquer crítica endereçada a esses e outros autores sobre tal matéria.

De todo modo, como propomos pesquisar os mecanismos de argumentação no funcionamento discursivo a partir do quadro teórico da Análise do Discurso, parece-nos que é fundamental situar que a abordagem discursiva de noções originalmente retóricas afasta-se das perspectivas que as concebem como partes de um jogo de estratégias arquitetadas por um orador plenamente consciente dos usos que ele faz dos recursos da linguagem para persuadir seu ouvinte. Isso significa que, nessa perspectiva, os estudos sobre a argumentação e seus conceitos tomados de empréstimo assumem as teses não idealista e não subjetivista da linguagem, conforme discutidas por Pêcheux, em seu livro Semântica e Discurso. O foco deste tipo de reflexão não incide sobre a argumentação de um orador específico, mas sobre os mecanismos discursivos de construção dos efeitos de argumentação que 
Linha D'Água (Online), São Paulo, v. 29, n. 2, p. 97-121, dez. 2016

constituem e caracterizam uma dada formação discursiva ${ }^{1}$, a qual determina o que pode e deve ser dito pelo sujeito discursivo.

Para esse propósito, este texto está organizado em três partes distintas. Primeiramente, apresentamos um breve panorama sobre o lugar do orador e do ouvinte ocupado nas teorias da argumentação e da argumentação no discurso, procurando destacar as concepções de sujeito vigentes, bem como os novos aportes que os estudos argumentativos receberam das perspectivas discursivas, especialmente dos trabalhos de Dominique Maingueneau e de Ruth Amossy. Num segundo momento, focalizamos a discussão na dimensão ideológica do discurso, assumindo uma perspectiva teórica específica, para, então, propor uma abordagem analítica da argumentação baseada na perspectiva materialista do discurso tal como preconizada pelo grupo de pesquisa de Michel Pêcheux. Por fim, procuramos ilustrar esta proposta de estudo, procedendo à análise de um pronunciamento parlamentar que antecedeu a instauração do Ato Institucional n. 5, em 13 de dezembro de 1968.

\section{Uma abordagem inicial da argumentação no discurso}

Em seu Manual de Retórica, Plebe \& Emanuele (1992 [1988]) dedicam um capítulo inteiro à crítica do que eles chamam de "o mito da argumentação". Começam por apontar o que seria uma contradição na obra de Perelman, acusando-o de "fazer o mundo da retórica deslizar do plano lógico-filosófico para o plano meramente sócio-psicológico" (p. 106) e, ainda, afirmam que:

Perelman constrói toda a técnica da argumentação visando ao que chama de “contato das mentes", o qual lhe assegura a meta de persuasão. Mas a persuasão e o contato das mentes são, na realidade, uma finalidade secundária ante o objetivo mais ilustre que, desde as suas origens, a retórica se impôs: a invenção e o desenvolvimento dos conceitos (PLEBE; EMANUELE, 1992 [1988], p. 108).

1 Conceito formulado por Michel Foucault, em A arqueologia do saber, de 1969, e reformulado por Pêcheux, no quadro teórico da Análise do Discurso, como "aquilo que, numa formação ideológica dada, isto é, a partir de uma posição dada numa conjuntura dada, determinada pelo estado da luta de classes, determina o que pode e deve ser dito (articulado sob a forma de uma arenga, de um sermão, de um panfleto, de uma exposição, de um programa etc.)" (PÊCHEUX, 1997 [1975], p. 160). 
Linha D'Água (Online), São Paulo, v. 29, n. 2, p. 97-121, dez. 2016

Entretanto, o que os autores do Manual de Retórica apontam como sendo um equívoco de Perelman é, justamente, o que nos parece ter sido a pedra de toque desse processo de revitalização da retórica na Modernidade: a restauração da dimensão subjetiva nos estudos retóricos. Não se trata de discutir o caráter mais ilustre ou menos ilustre dos objetivos da retórica clássica, mas de sublinhar que a arte retórica fora orientada, desde sua origem, em razão de uma intervenção concreta do indivíduo em seu grupo social por meio da linguagem, em que não se concebe a abordagem da invenção (a inventio retórica) alijada de um "para quem inventar" e de um "para que inventar", ou seja, da importância do papel do orador e do seu auditório na atividade argumentativa² ${ }^{2}$.

Diferentemente da posição de Plebe \& Emanuele (1992 [1988]), Plantin entende que o Tratado da argumentação, de Perelman \& Olbrechts-Tyteca (1996 [1958]), e Os usos do argumento, de Toulmin (2006 [1958]), embora apresentem horizontes teóricos distintos, são obras dotadas de um mesmo objetivo, pois seus autores "pesquisam, no pensamento argumentativo, um meio de fundar uma racionalidade específica, operando nas relações humanas" (PLANTIN, 1996, p. 10, tradução nossa) $)^{3}$. Guardadas as diferenças, a concepção de argumentação assumida por Perelman \& Olbrechts-Tyteca (1996 [1958]) e Toulmin (2006 [1958]) não se confunde com a ideia de demonstração construída por meio de raciocínio lógico ${ }^{4}$, uma vez que ambos consideram a argumentação situada em contexto.

Igualmente inscrita no paradigma da virada pragmática nos estudos da linguagem, Amossy reforça a abordagem da comunicação e da interação entre os participantes da troca argumentativa e ressalta a dimensão institucional e social

2 Conforme Amossy (2011 [2008], p. 129), "a retórica clássica, definida como a arte de persuadir - [é], nesse sentido, sinônimo de argumentação".

3 No original: "Ils recherchent dans la pensée argumentative un moyen de fonder une racionalité spécifique, à l'œuvre dans les affaires humaines.".

4 Nesse sentido, podemos dizer que há uma reinscrição dessas teorizações na tradição da retórica aristotélica, na qual o tipo de raciocínio desenvolvido não é o demonstrativo, tal como o é na Dialética, mas sim o argumentativo, pois a arte retórica versa sobre aquilo que é provável, que é do âmbito da opinião, apresentando, como ponto de partida, premissas verossímeis ao invés de verdadeiras: a retórica é "a capacidade de descobrir o que é adequado a cada caso com o fim de persuadir" (ARISTÓTELES, 1998 [c.330-326 a.C], p. 48). 
Linha D'Água (Online), São Paulo, v. 29, n. 2, p. 97-121, dez. 2016

da análise argumentativa, reafirmando, assim, a distinção entre duas maneiras de considerar a argumentação:

Passa-se, então, do domínio dos universais, que implica a retórica orientada pelo logos como razão atemporal, ao domínio do social em sua relatividade e suas variações históricas e culturais (AMOSSY, 2011 [2008], p. 133).

Nesse horizonte teórico, as categorias de análise que despertam interesse não são os elementos da ordem da demonstração lógica, mas sim os da língua natural. Segundo Amossy, destacam-se, nessa abordagem, não "o silogismo, o entimema, a analogia" nem o "encadeamento de proposições lógicas", por exemplo, mas sim "o uso de conectores ou de dêiticos, [...] a pressuposição e o implícito, as marcas de estereotipia, a ambiguidade, a polissemia, a metáfora, a repetição, o ritmo" (AMOSSY, 2011 [2008], p. 132).

Um exemplo dessa distinção acerca da acepção de argumentação pode ser encontrado no artigo de Maingueneau (2011 [1994]) intitulado "Argumentação e Análise do Discurso (Reflexões a partir da segunda Provincial)", no qual dirige uma crítica ao estudo de Ducrot (1971) dedicado à análise da argumentação da Segunda Provincial, escrita por Pascal em 1656.

Em linhas gerais, o autor da Provincial discute a posição dos dominicanos sobre a "graça suficiente", apresentando aí três teses: a dos jesuítas, a dos jansenistas e a dos próprios dominicanos. O método de Ducrot, segundo Maingueneau:

[...] consiste em mostrar que o raciocínio de Pascal se traduz com exatidão no formalismo do cálculo dos predicados, e que essa surpreendente tradução tornou-se possível por meio de uma interpretação lógico-matemática do adjetivo suficiente (MAINGUENEAU, 2011 [1994], p. 75).

Maingueneau entende que, embora Ducrot aplique corretamente os cálculos de predicados e, com base nisso, conclua que Pascal cometera um erro, do ponto de vista da análise do discurso, o autor da Segunda Provincial utiliza-se de uma linguagem de não especialista, para criar a imagem de um homem de bom senso que dirige sua fala a outros homens de bom senso, o que caracteriza não um erro, 
Linha D'Água (Online), São Paulo, v. 29, n. 2, p. 97-121, dez. 2016

mas o uso de um recurso argumentativo voltado à construção da identificação do autor com seu leitor.

Nesse ponto de vista, a análise argumentativa da Segunda Provincial deveria voltar-se não para os cálculos de predicados, mas sim para a compreensão da situação de enunciação da produção discursiva, do próprio gênero epistolar e do ethos discursivo, uma vez que:

[...] quando o analista do discurso se volta para a argumentação, não é com a intenção de estabelecer o modelo dos processos de validação, mas de relacioná-los a um gênero do discurso histórica e socialmente situado (MAINGUENEAU, 2011 [1994], p. 71).

Numa linha de trabalho próxima a de Maingueneau, Amossy também situa a argumentação na dimensão sócio-histórica do discurso, pois defende uma perspectiva de estudo da argumentação no discurso "que relaciona a fala a um lugar social e a instâncias institucionais" (AMOSSY, 2007, p. 123). Nas palavras da autora, a argumentação:

[...] depende das possibilidades da língua e das condições sociais e institucionais que determinam parcialmente o sujeito, fora dos quais a orientação ou a dimensão argumentativa do discurso não pode ser apreendida com discernimento (AMOSSY, 2007, p. 128).

É importante observar que o processo de restauração da dimensão subjetiva nos estudos retórico-argumentativos iniciado por Perelman \& Olbrechts-Tyteca (1996 [1958]) e Toulmin (2006 [1958]) encontra-se, de certo modo, reinscrito na concepção de argumentação formulada nos trabalhos de Maingueneau (2011 [1994]) e de Amossy (2007, 2011 [2008]), estabelecendo-se aí uma relação de continuidade discursiva.

No entanto, essa reinscrição teórica é atravessada pelas condições de produção de seu tempo e recebe, assim, aportes das teorias linguísticas, sociais e filosóficas reconhecidas sob a égide do pós-estruturalismo. Desse modo, enquanto Maingueneau (2011 [1994]) focaliza o sujeito argumentador como um ethos - um modo de enunciar e de se representar - associado a um gênero do discurso situado 
Linha D'Água (Online), São Paulo, v. 29, n. 2, p. 97-121, dez. 2016

sócio-historicamente, Amossy (2007, 2011 [2008]) compreende esse sujeito argumentador como determinado parcialmente pelas condições social e institucional que o circunscrevem. A esse respeito, Amossy (2013), em seu livro L'argumentation dans le discours, incorpora à análise argumentativa a tese do descentramento do sujeito, afirmando que a argumentação no discurso é uma disciplina que:

[...] se recusa a pôr na origem do discurso "um sujeito enunciador individual que seria dono de si mesmo” (MAZIÈRE, 2005, p. 5): o locutor, como o auditório, é sempre atravessado pela fala do outro, pelas ideias preconcebidas e pelas evidências de uma época e, por isso, condicionado pelas possibilidades de seu tempo (AMOSSY, 2013, p. 8, tradução nossa).

Ao assumir que o discurso do locutor é constituído pelo atravessamento da fala e das ideias preconcebidas do auditório e das evidências e verdades de uma época, Amossy associa, consequentemente, a essa concepção de sujeito descentrado uma perspectiva da interdiscursividade na argumentação. A esse respeito, a própria autora afirma que:

[...] a heterogeneidade constitutiva é um dos fundamentos da fala argumentativa na medida em que esta, necessariamente, reage à palavra do outro, quer seja para retomá-la, modificá-la ou refutá-la (AMOSSY, 2011 [2008], p. 133).

Nesse sentido, a proposta de análise da argumentação no discurso formulada por Amossy coaduna, novamente, com o trabalho de Maingueneau, quando este afirma que "o exercício da polêmica presume a partilha do mesmo campo discursivo, [em que] é preciso desqualificar o adversário, porque ele é constituído exatamente do Mesmo que nós, mas deformado, invertido" (1997 [1987], p. 125). De fato, ambos os autores retomam o conceito de heterogeneidade discursiva preconizado por Authier-Revuz (2004 [1982]), para a qual a concepção de uma heterogeneidade constitutiva do sujeito e de seu discurso recobre a ideia de que o outro está constitutivamente presente no sujeito e no seu discurso, enquanto que a noção de heterogeneidade mostrada abarca as formas que inscrevem o outro no fio discursivo e representam a negociação do sujeito enunciador com a heterogeneidade constitutiva de seu discurso. 
Do exposto até aqui, podemos notar que o trabalho de Maingueneau (2011 [1994]) e, principalmente, os de Amossy (2007, 2011 [2008], 2013) promoveram a ampliação do escopo dos estudos sobre a argumentação para as questões relacionadas à interdiscursividade, ao contexto sócio-histórico, ao lugar institucional ocupado pelos sujeitos situados em interações argumentativas e, portanto, à própria natureza desse sujeito.

Contudo, parece-nos que, nesse quadro teórico, há uma lacuna nada desprezível que merece atenção: trata-se da dimensão ideológica da argumentação no discurso. Assim, penso que é possível extrapolar ainda mais os limites dos estudos argumentativos, considerando, por exemplo, o papel dos mecanismos da argumentação na produção discursiva dos efeitos de evidência ideológica, questão cara à Análise do Discurso assim formulada por Pêcheux:

É a ideologia que fornece as evidências pelas quais "todo mundo sabe" o que é um soldado, um operário, um patrão, uma fábrica, uma greve, etc., evidências que fazem com que uma palavra ou um enunciado "queiram dizer o que realmente dizem” [...] (PÊCHEUX, 1997 [1975], p. 160).

Assim, meu propósito para o tópico seguinte deste trabalho consiste em apresentar alguns dos mecanismos discursivos mobilizados para a produção dos efeitos de argumentação e sua relação com a posição ideológica materializada no discurso.

\section{Para uma abordagem materialista da argumentação no discurso}

\subsection{Orador e ouvinte como ilusão necessária construtora do sujeito}

Para refletir acerca da argumentação numa teoria materialista do discurso, comecemos, primeiramente, por compreender a relação entre ideologia e sujeito do discurso. Pêcheux contrapõe a concepção materialista do sujeito à concepção idealista, apontando que o erro central da visão idealista consiste em:

[...] considerar as ideologias como idéias e não como forças materiais e [...] em conceber que elas têm sua origem nos sujeitos, quando na verdade elas 
Linha D'Água (Online), São Paulo, v. 29, n. 2, p. 97-121, dez. 2016

'constituem os indivíduos em sujeitos', para retomar a expressão de L. Althusser" (1997 [1975], p. 129).

Retomando o que expusemos na introdução, não estava no horizonte de Aristóteles, em sua Retórica, e de Perelman \& Olbrechts-Tyteca, em seu Tratado, uma discussão a respeito da concepção de sujeito, o que torna injusta qualquer crítica dirigida a esses autores sobre essa questão. Todavia, é preciso sublinhar que uma análise discursiva da argumentação fundamentada na tese não idealista da linguagem não assume as perspectivas de estudo que tratam a argumentação como um jogo de estratégias arquitetadas por um orador plenamente consciente dos usos que ele faz dos recursos da linguagem para persuadir seu ouvinte. Tal concepção idealista pode ser encontrada na seguinte explicação de Aristóteles sobre a diferença entre retórica e dialética:

[...] é igualmente evidente que quem melhor puder teorizar sobre as premissas - do que e como se produz um silogismo - também será o mais hábil em entimemas, porque sabe a que matérias se aplica o entimema e que diferenças este tem dos silogismos lógicos (ARISTÓTELES, 1998 [c.330-326 a.C], p. 46).

E, igualmente, em Perelman \& Olbrechts-Tyteca (1996 [1958]), ao tratar das premissas da argumentação:

O orador, utilizando as premissas que servirão de fundamento à sua construção, conta com a adesão de seus ouvintes às proposições iniciais, mas estes lha podem recusar [...] (Id., p. 73).

Nesses excertos, temos dois exemplos do que Pêcheux chama de concepção idealista do sujeito, uma vez que podemos notar que o orador é aquele que teoriza sobre as premissas, produz um silogismo, sabe aplicar o entimema e utiliza as premissas, ou seja, o orador é o responsável e o centro organizador de todo o ato argumentativo, afigurando-se como a origem dos sentidos do que é proposto na argumentação. 
Se considerarmos, conforme Fuchs (1985, p. 112), que a retórica é uma ancestral da teoria da enunciação ${ }^{5}$, no sentido de que "[...] a perspectiva enunciativa estava presente na retórica aristotélica”, é coerente afirmar que, de acordo com Fuchs \& Pêcheux (2001 [1975], p. 175), essa mesma problemática da concepção idealista do sujeito se faz presente nas teorias enunciativas, quando "elas se contentam em reproduzir no nivel teórico esta ilusão do sujeito, através da ideia de um sujeito enunciador portador de escolha, intenções, decisões etc. na tradição de Bally, Jakobson, Benveniste [...]”.

Por outro lado, no entanto, um analista do discurso - que rejeita a visão idealista da linguagem, apoiando-se no pressuposto teórico althusseriano reformulado por Pêcheux, a saber "[as ideologias] não têm sua origem nos sujeitos, na verdade elas 'constituem os individuos em sujeitos"' (PÊCHEUX, 1997 [1975], p. 129) - compreende que a ideologia e a sua materialização na língua constituem os sujeitos, pois o contrário disso - reiteramos: do ponto de vista de uma teoria do discurso baseada na tese do assujeitamento ideológico e do sujeito cindido entre o consciente e o inconsciente - constitui uma ilusão, aliás ilusão necessária ${ }^{6}$ à constituição do sujeito. Desse modo, se, na argumentação, a defesa de uma tese, em contraposição a outra(s) tese(s), corresponde, em termos discursivos, a uma tomada de posição do sujeito enunciador perante a formação discursiva que o domina, essa

[...] tomada de posição não é, de modo algum, concebível como um 'ato originário' do sujeito-falante: ela deve, ao contrário, ser compreendida como o efeito, na forma-sujeito, da determinação do interdiscurso como discurso-transverso [...] (PÊCHEUX, 1997 [1975], p. 171-172).

5 Nos termos de Fuchs (1985, p. 112): "De fato, esta retórica se sustenta, enquanto princípio, na consideração daquilo que chamamos hoje 'a situação de enunciação'. 'Podemos distinguir três elementos em qualquer discurso: aquele que fala, o assunto sobre o qual se fala, aquele a quem se fala', diz Aristotéles [em sua Retórica]. Essa filiação, há muito tempo esquecida, em particular pelos linguistas, começa a renascer nos últimos anos: a 'história do estudo das estratégias discursivas não é nada mais do que a história da retórica', afirma Le Guern (1978)".

6 Conforme Pêcheux \& Fuchs (2001 [1975], p. 239), "o termo 'ilusão necessária' foi introduzido pela primeira vez por P. de Goffic" na obra coletiva $A$ propos des relatives, organizada por Fuchs e Milner, em 1974. 
Linha D'Água (Online), São Paulo, v. 29, n. 2, p. 97-121, dez. 2016

Assim, se a análise da argumentação em perspectiva discursiva confere unidade ao orador e seu ouvinte, isso apenas ocorre com base nessa ilusão necessária construtora do sujeito, o que Fuchs \& Pêcheux (2001 [1975]) inicialmente formularam como o esquecimento n. 1 :

É este fato de toda sequência [discursiva] pertencer necessariamente a uma formação discursiva para que seja "dotada de sentido" que se acha recalcado para o (ou pelo?) sujeito e recoberto para este último, pela ilusão de estar na fonte do sentido, sob a forma da retomada pelo sujeito de um sentido universal preexistente [...] (FUCHS; PÊCHEUX, 2001 [1975], p. 169).

Antes de prosseguir, é preciso fazer uma ressalva. $\mathrm{O}$ conceito de esquecimento foi, inicialmente, formulado por Pêcheux \& Fuchs (2001 [1975]), com base na primeira tópica de Freud - ou seja, os três sistemas que compõem o aparelho psíquico: o inconsciente, o pré-consciente e o consciente - na qual eles utilizam "a oposição entre o 'sistema pré-consciente/consciente' e o 'sistema inconsciente' para definir dois tipos radicalmente diferentes de 'esquecimentos' inerentes ao discurso" (PÊCHEUX, 1997 [1975], p. 173). Entretanto, em seu texto anexo ao Semântica e Discurso, "Só há causa daquilo que falha ou o inverno político francês: início de uma retificação", Pêcheux (1997 [1975]) apresenta uma autocrítica, apontando o conflito - até então não observado - entre o conceito psicanalítico de recalque e a ideia platônica de esquecimento ou de apagamento, "pois os traços inconscientes do significante não são jamais 'apagados' ou 'esquecidos', mas trabalham, sem se deslocar, na pulsação sentido/non sens do sujeito dividido” (Id., p. 300). A retificação reside em que o recalcado não pode ser confundido com o esquecido, porque ele simplesmente não desaparece ou é recoberto, mas se manifesta incessantemente sob as formas do lapso, do ato falho etc. (Id., p. 300).

Dito isso, podemos propor, em síntese, que o orador e o ouvinte - sujeitos participantes da argumentação - são considerados como noções que reforçam a ilusão necessária de centralidade do sujeito discursivo e que somente podem ser tomados emprestadas enquanto efeitos de sentido vinculados a um sujeito discursivo cindido e descentrado. 
Linha D'Água (Online), São Paulo, v. 29, n. 2, p. 97-121, dez. 2016

\subsection{A argumentação no funcionamento discursivo}

Para compreender de que maneira podemos abarcar as noções retórico-argumentativas de orador e de ouvinte, de acordo com a concepção de sujeito discursivo apresentada e assumida neste trabalho, propomos retomar a noção de funcionamento discursivo tal como postulada por Pêcheux (2001 [1969]) e, depois, explorada por Eni Orlandi (2011 [1983]).

Pêcheux define sua noção de funcionamento discursivo, afirmando que:

[...] os fenômenos linguísticos de dimensão superior à frase podem efetivamente ser concebidos como um funcionamento, mas com a condição de acrescentar imediatamente que este funcionamento não é integralmente linguístico, no sentido atual desse termo e que não podemos defini-lo senão em referência ao mecanismo de colocação dos protagonistas e do objeto de discurso, mecanismo que chamamos “condições de produção" do discurso (PÊCHEUX, 2001 [1969]), p. 78).

Antes de prosseguir com a reflexão, é preciso fazer algumas ponderações a respeito das críticas dirigidas a essa teorização apresentada na chamada AAD-69, sobretudo ao viés psicologizante e sociologizante de algumas de suas formulações. Sobre esse aspecto, Fuchs \& Pêcheux (2001 [1975]) esclarecem que o problema que havia na formulação do termo "condições de produção" apresentada, em 1969, em "Análise Automática do Discurso (AAD-69)", residia em uma ambiguidade que "designava ao mesmo tempo o efeito das relações de lugar nas quais se acha inscrito o sujeito e a 'situação' no sentido concreto e empírico do termo, isto é, o ambiente material e institucional, os papeis mais ou menos conscientemente colocados em jogo, etc." (Id., p. 171). Ao reconhecer uma certa visão idealista que permeava a natureza do sujeito e de sua situação de interação, Fuchs \& Pêcheux (2001 [1975]) afirmam que o que faltava, para resolver as formulações ambíguas expressas naquele texto de 1969 acerca das condições de produção do discurso, era justamente "uma teoria não subjetivista da constituição do sujeito em sua situação concreta de enunciador" (Id., p. 171). Essa demanda foi, então, atendida por meio de duas retificações que se encontram, inicialmente, em Fuchs \& Pêcheux (2001 [1975]) e em Pêcheux (1997 [1975]), e, depois, em uma nova revisão produzida 
Linha D'Água (Online), São Paulo, v. 29, n. 2, p. 97-121, dez. 2016

em 1978, que foi publicada na forma de anexo nas traduções inglesa e brasileira de Les vérités de La Palice.

Uma vez que já apresentamos, neste trabalho, o conceito de sujeito discursivo numa concepção não subjetivista, podemos iniciar, sem esses conflitos teóricos, nossa exposição acerca dos efeitos de argumentação no funcionamento discursivo e, logo, sua relação com as condições de produção do discurso. Retomando a citação de Pêcheux sobre a definição da noção de funcionamento discursivo, não é demais destacar que o que está em jogo nessa reformulação do conceito de funcionamento linguístico de Saussure proposta por Pêcheux não é apenas o linguístico, mas também o discursivo. Isso significa que o mecanismo de colocação dos protagonistas e do objeto de discurso - as "condições de produção" do discurso - consiste num processo de construção sócio-histórica e ideológica dos sentidos, que se materializa na articulação entre a base linguística e os processos discursivos.

Nessa mesma linha, Orlandi retoma os postulados de Pêcheux, afirmando que:

A noção fundamental é a de funcionamento. Quer dizer, do ponto de vista da análise do discurso, o que importa é destacar o modo de funcionamento da linguagem, sem esquecer que esse funcionamento não é integralmente linguístico, uma vez que dele fazem parte as condições de produção, que representam o mecanismo de situar os protagonistas e o objeto do discurso (ORLANDI, 2011 [1983]), p. 117).

Mais adiante, Orlandi destaca a relevância dessa noção ao afirmar que "o funcionamento discursivo [...] é a atividade estruturante de um discurso determinado, por um falante determinado, para um interlocutor determinado, com finalidades específicas" (ORLANDI, 2011 [1983]), p. 125). É preciso destacar que a retomada de Orlandi se justifica pela ênfase que a autora aplica não apenas na ideia de representação imaginária dos interlocutores construída no e pelo discurso, mas, sobretudo, na ideia da relação que esses interlocutores mantêm com a formação ideológica.

Desse modo, passemos a observar como Pêcheux já se preocupava, desde a AAD69, com a argumentação no funcionamento discursivo. Embora extensa, acompanhemos a citação: 
Linha D'Água (Online), São Paulo, v. 29, n. 2, p. 97-121, dez. 2016

Se prosseguirmos com a análise do discurso político - que serve aqui apenas de representante exemplar de diversos tipos de processos discursivos - veremos que, por outro lado, ele deve ser remetido às relações de sentido nas quais é produzido: assim, tal discurso remete a tal outro, frente ao qual é uma resposta direta ou indireta, ou do qual ele "orquestra" os termos principais ou anula os argumentos. Em outros termos, o processo discursivo não tem, de direito, início: o discurso se conjuga sempre sobre um discursivo prévio, ao qual ele atribui o papel de matéria-prima, e o orador sabe que quando evoca tal acontecimento, que já foi objeto de discurso, ressuscita no espírito dos ouvintes o discurso no qual este acontecimento era alegado, com as "deformações" que a situação presente introduz e da qual pode tirar partido.

Isso implica que o orador experimente de certa maneira o lugar de ouvinte a partir de seu próprio lugar de orador: sua habilidade de imaginar, de preceder o ouvinte é, às vezes, decisiva se ele sabe prever, um tempo hábil, onde este ouvinte o "espera". Esta antecipação do que o outro vai pensar parece constitutiva de qualquer discurso [...] (PÊCHEUX, 2001 [1969], p. 77).

Desse excerto, podemos destacar, entre tantos conceitos, alguns que podem nos parecer fundamentais para a compreensão da argumentação no discurso: a interdiscursividade ("um discurso remete a tal outro"; "o discurso se conjuga sempre sobre um discursivo prévio"); o esquecimento n. 1 ("ele 'orquestra' os termos principais ou anula os argumentos"); o esquecimento n. 2 ("o orador sabe que [...]"); a deriva do sentido ("este acontecimento era alegado, com as "deformações" que a situação presente introduz"); as formações imaginárias ("Isso implica que o orador experimente de certa maneira o lugar de ouvinte a partir de seu próprio lugar de orador"); a antecipação ("Esta antecipação do que o outro vai pensar parece constitutiva de qualquer discurso").

Devido aos limites deste trabalho, iremos me eximir de discutir todas as possibilidades acima aventadas para o estudo da argumentação no discurso, para apenas sublinhar de que maneira podemos nos apropriar do que Pêcheux diz sobre o mecanismo discursivo da antecipação, especificamente no que tange à sua afirmação sobre o orador experimentar o lugar de ouvinte a partir de seu próprio lugar de orador, lembrando, mais uma vez, que orador e ouvinte são concebidos como forma-sujeito.

Entendemos que esse lugar onde o orador "espera" o ouvinte - e, para completar o quadro, onde o ouvinte também "espera" o orador; onde Proponente e 
Linha D'Água (Online), São Paulo, v. 29, n. 2, p. 97-121, dez. 2016

Oponente ${ }^{7}$ se "esperam" - constitui-se por meio do conjunto do que pode e deve ser dito pelo sujeito de um dado discurso, ou seja, são as palavras, os enunciados e as proposições que se esperam materializar em um certo discurso inscrito em uma determinada formação discursiva, inclusive as palavras que denominam os efeitos de identidade de si e do outro. Em outros termos, não se trata de "esperar" apenas o outro, mas o lugar de onde esse outro fala.

É desse modo que mobilizamos o conceito de formações imaginárias, considerando que, na concepção de Pêcheux (2001 [1969]), "o que funciona nos processos discursivos é uma série de formações imaginárias que designam o lugar que $\mathrm{A}$ e $\mathrm{B}$ se atribuem cada um a si e ao outro, a imagem que eles se fazem de seu próprio lugar e do lugar do outro" (Id., p. 82) por meio das questões implícitas "quem sou eu para lhe falar assim?”, "quem é ele para que eu lhe fale assim?”, "quem sou eu para que ele me fale assim?" e "quem é ele para que me fale assim?” (Id., p. 83), além de designar também o seu referente com as questões implícitas "de que lhe falo assim" e "de que ele me fala assim" (Id., p. 84).

Vale acompanhar, nas Figuras 1 e 2, como Pêcheux esquematiza seu conceito de formações imaginárias:

7 Conforme Plantin (2008 [2005], p. 64), Proponente, Oponente, Terceiro são os papeis argumentativos do modelo dialogal, no qual "situação argumentativa típica é definida pelo desenvolvimento e pelo confronto de pontos de vista em contradição, em resposta a uma mesma pergunta". 
Linha D'Água (Online), São Paulo, v. 29, n. 2, p. 97-121, dez. 2016

\begin{tabular}{|c|c|c|}
\hline $\begin{array}{l}\text { EXPRESSÃO QUE } \\
\text { DESIGNA AS FORMAÇÕES } \\
\text { IMAGINÁRIAS }\end{array}$ & SIGNIFICAÇÃO DA EXPRESSÃO & $\begin{array}{l}\text { QUESTÃO IMPLICITA CUJA "RESPOSTA" } \\
\text { SUBENTENDE A FORMAÇÃO } \\
\text { IMAGINÁRIA CORRESPONDENTE }\end{array}$ \\
\hline $\mathrm{I}_{\mathrm{A}}(\mathrm{A})$ & $\begin{array}{c}\text { Imagem do lugar de A para o } \\
\text { sujeito colocado em A }\end{array}$ & "Quem sou eu para lhe falar assim?" \\
\hline $\mathrm{I}_{\mathrm{A}}(\mathrm{B})$ & $\begin{array}{l}\text { Imagem do lugar de B para o } \\
\text { sujeito colocado em A }\end{array}$ & $\begin{array}{l}\text { "Quem é ele para que eu lhe fale } \\
\text { assim?" }\end{array}$ \\
\hline $\mathrm{I}_{\mathrm{B}}(\mathrm{B})$ & $\begin{array}{l}\text { Imagem do lugar de B para o } \\
\text { sujeito colocado em B }\end{array}$ & $\begin{array}{c}\text { "Quem sou eu para que ele me fale } \\
\text { assim?" }\end{array}$ \\
\hline $\mathrm{I}_{\mathrm{B}}(\mathrm{A})$ & $\begin{array}{l}\text { Imagem do lugar de A para o } \\
\text { sujeito colocado em B }\end{array}$ & $\begin{array}{c}\text { "Quem é ele para que me fale } \\
\text { assim?" }\end{array}$ \\
\hline
\end{tabular}

Figura 1: Formações imaginárias referentes aos protagonistas do discurso

Fonte: Pêcheux (2001 [1969], p. 83).

\begin{tabular}{|c|c|c|}
\hline $\begin{array}{c}\text { EXPRESSÕES QUE } \\
\text { DESIGNAM AS FORMAÇÕES } \\
\text { IMAGINÁRIAS }\end{array}$ & SIGNIFICAC̣ÃO DA EXPRESSÃO & $\begin{array}{l}\text { QUESTÃO IMPLÍCITA CUJA "RESPOSTA" } \\
\text { SUBENTENDE A FORMAÇÃO } \\
\text { IMAGINÁRIA CORRESPONDENTE }\end{array}$ \\
\hline IA $(\mathrm{R})$ & "Ponto de vista" de A sobre R & "De que lhe falo assim?" \\
\hline IB $(\mathrm{R})$ & "Ponto de vista" de B sobre R & "Que de ele me fala assim?" \\
\hline
\end{tabular}

Figura 2: Formações imaginárias referentes aos objetos do discurso

Fonte: Pêcheux (2001 [1969], p. 84).

Insistimos, novamente, que é preciso ter claro que as formações imaginárias não são um jogo de imagens projetadas por sujeitos empíricos, mas sim construções da ordem do simbólico fundadas no mecanismo da antecipação, constitutivamente marcado pela interdiscursividade, pois, segundo Pêcheux, o processo discursivo não tem, de direito, início: "o discurso se conjuga sempre sobre um discursivo prévio” (2001 [1969], p. 77). Nessa mesma perspectiva, em um artigo que trata, 
Linha D'Água (Online), São Paulo, v. 29, n. 2, p. 97-121, dez. 2016

especificamente, da argumentação, Orlandi (1998) corrobora as formulações de Pêcheux, afirmando que a argumentação é parte dos efeitos de sentido entre os sujeitos do discurso e que, assim, duas dimensões discursivas estão presentes na argumentação: a antecipação (as formações imaginárias) e o interdiscurso:

Há duas noções que estão na base do mecanismo da argumentação e que desempenham um papel importante na articulação da linguagem com a ideologia e o político: 1. a noção de antecipação, sustentada pelo funcionamento das formações imaginárias (posições-sujeito); 2. a noção de esquecimento ligada ao interdiscurso (exterioridade discursiva) (ORLANDI, 1998, p. 73-74).

Do exposto, podemos dizer que também os trabalhos de Fuchs \& Pêcheux (2001 [1975]), Pêcheux (2001 [1969]), 1997 [1975]) e Orlandi (1998), situados na análise do discurso dita de linha francesa, inscrevem-se, à sua maneira, no processo de restauração da dimensão subjetiva nos estudos sobre argumentação iniciado por Perelman \& Olbrechts-Tyteca (1996 [1958]) e Toulmin (2006 [1958]), porém numa relação de continuidade discursiva distinta daquela dos trabalhos de Maingueneau (2011 [1994]) e de Amossy (2007, 2011 [2008], 2013).

\section{A argumentação num pronunciamento de defesa do mandato parlamentar}

À guisa de ilustração, iremos proceder à análise do pronunciamento parlamentar do deputado federal e líder da minoria Mário Covas Júnior (MDB/SP) proferido na sessão de 12 de dezembro de 1968, em virtude do pedido de cassação do mandato do deputado Márcio Moreira Alves $(\mathrm{MDB} / \mathrm{GB})^{8}$ por supostamente ter ofendido às Forças Armadas em seus pronunciamentos de 2 e 3 de setembro de 1968 a respeito do Estado de exceção em que se encontrava o Brasil naquele período. Cumpre dizer que a Câmara Federal negou o pedido de concessão de licença solicitado pelo

8 MDB (Movimento Democrático Brasileiro) foi o partido político que abrigou os opositores ao regime ditatorial militar após a instauração do bipartidarismo no Brasil pelo Al-2, de 27 de outubro de 1965. A sigla GB diz respeito ao extinto estado da Guanabara. 
governo militar, o que desencadeou uma resposta imediata por parte do regime militar: a edição do Ato Institucional n. 5, em 13 de dezembro de 1968.

Assim, desse pronunciamento, abordaremos apenas um dos argumentos apresentados devido à sua importância na argumentação do parlamentar. Acompanhemos a seguinte sequência discursiva ${ }^{9}$ :

Há uma constante neste problema, e o desenrolar dos acontecimentos o evidencia. Muitos tentam justificar o voto; outros pleiteiam a validade da tese. Creio, entretanto, que em todo o elenco de autoridades, em todo o rol de fontes citadas, um nome foi esquecido. As razões desconheço. Porém, minha condição de engenheiro certamente me absolverá, se, inspirando-me em sua lição, a tomar para guia e orientação. Trata-se do atual ocupante do Ministério da Justiça, o Dr. Luiz Antônio da Gama e Silva. Leio-lhe um parecer a respeito deste problema; e este parecer está exarado num outro processo, em curso nesta Casa, em que solicita a licença para processar o Deputado Hermano Alves.

Eis S.Exa. em seu ofício ao Procurador da Justiça Militar:

"Realmente os artigos publicados pelo citado parlamentar configuram, indubitavelmente, violações dos preceitos expressos nos artigos 14, etc., do Decreto-Lei 314, porque:

a) por sua falsidade, tendenciosidade e deturpação põe em perigo o bom nome, a autoridade e o prestígio do Brasil;

b) constituem atos destinados à guerra revolucionária ou subversiva;

c) ofendem a honra e a dignidade do Exmo. Sr. Presidente da República diretamente ou através de seus Ministros de Estado e auxiliares;

d) incitam, publicamente, a subversão da ordem política e social e animosidade entre as instituições civis e as Forças Armadas".

Mais adiante, conclui S.Exa, de forma límpida e cristalina, a orientar-nos no atual problema.

"No tocante, porém, aos discursos proferidos na tribuna da Câmara dos Deputados, não se afigura, in casu, exista qualquer delito, diante da indenidade assegurada do Art. 34, caput, da Constituição, e porque o abuso do direito político praticado, sem dúvida, pelo incontinente Deputado não atenta contra a ordem democrática nem visa à prática de corrupção, e somente quando o abuso do direito tende a esses objetivos ou a qualquer deles, se justifica a medida prevista no art. 151 da Lei Maior."

9 Conforme Courtine (2009 [1981]). 
Linha D'Água (Online), São Paulo, v. 29, n. 2, p. 97-121, dez. 2016

Creio, Sr. Presidente, creio, Srs. Deputados, que a frente poderá ser contestada. Eu entretanto me auto-absolvo, porque, sendo engenheiro, acho inteiramente válido consultar a figura do Ministro da Justiça neste episódio, desta natureza (DIÁRIO OFICIAL DA CÂMARA DOS DEPUTADOS, 2000, p. 102-103).

Baseando-nos nas técnicas argumentativas apresentadas no Tratado da argumentação, podemos resumir o esquema argumentativo construído no pronunciamento de Mário Covas à produção de um argumento de autoridade para fundamentar uma regra a partir da argumentação pelo exemplo, o qual se afigura com estatuto de fato ${ }^{10}$, visto que "seja qual for a maneira pela qual o exemplo é apresentado, em qualquer área que se desenvolva a argumentação, o exemplo invocado deverá [...] usufruir do estatuto de fato [...]" (PERELMAN; OLBRECHTS-TYTECA, 1996 [1958], p. 402).

Pormenorizando, nesse pronunciamento parlamentar, produz-se a argumentação pelo exemplo, quando o orador invoca um fato precedente para fundamentar uma regra, ou seja, o parlamentar invoca o exemplo de outro deputado - objeto do parecer do Ministro da Justiça Gama e Silva citado no pronunciamento de Mário Covas -, mostrando que "[...] aos discursos proferidos [pelo deputado Hermano Alves] na tribuna da Câmara dos Deputados, não se afigura, in casu, exista qualquer delito, diante da indenidade assegurada do Art. 34, caput, da Constituição [...]”.

Segundo os autores do Tratado da argumentação, "em Direito, invocar o precedente significa tratá-lo como um exemplo que fundamenta uma regra [...]” (Id., p. 400). Assim, a regra ou a generalização a ser construída pela argumentação de Mário Covas é que, igualmente ao deputado Hermano Alves, o deputado Márcio Moreira Alves, em seus pronunciamentos feitos na tribuna da Câmara Federal em 2 e de 3 de setembro de 1968, não atenta contra a ordem democrática nem visa à corrupção, o que lhe preserva o direito à inviolabilidade, garantida no artigo $34 \mathrm{da}$ Constituição Federal de 1967, e o afasta da suspensão dos direitos políticos prevista em seu artigo 151.

10 Conforme Perelman \& Olbrechts-Tyteca (1996 [1958], p. 76), "só estamos em presença de um fato, do ponto de vista argumentativo, se podemos postular a seu respeito um acordo universal, não controverso". 
Linha D'Água (Online), São Paulo, v. 29, n. 2, p. 97-121, dez. 2016

É interessante notar que essa argumentação pelo exemplo é produzida em articulação com o argumento de autoridade, que, segundo Perelman \& OlbrechtsTyteca (1996 [1958]), é assim compreendido:

Muitos argumentos são influenciados pelo prestígio. [...]. Mas existe uma série de argumentos cujo alcance é totalmente condicionado pelo prestígio (Id., p. 237).

$\mathrm{O}$ argumento de prestígio mais nitidamente caracterizado é o argumento de autoridade, o qual utiliza atos ou juízos de uma pessoa ou de um grupo de pessoas como meio de prova a favor de uma tese (Id., p. 348).

O ponto central de nossa análise discursiva da argumentação reside, portanto, no mecanismo de construção desse argumento de autoridade. Primeiramente, trata-se da inscrição de um discurso-outro no discurso de um deputado oposicionista do MDB. É o discurso do ministro que encaminhou o pedido de licença para processar Márcio Moreira Alves, o discurso do Ministro da Justiça Gama e Silva, que irrompe no fio discursivo do deputado Mário Covas, na qualidade de argumento de autoridade. Por meio do discurso direto, uma das formas do discurso relatado ${ }^{11}$, o discurso do oposicionista é atravessado e constituído pela formação discursiva da legalidade que sustenta a pretensa legitimidade do regime ditatorial.

Exploremos agora a circulação desse argumento de autoridade na constituição dos sujeitos colocados em situação de argumentação: orador e ouvinte. No funcionamento discursivo desse pronunciamento parlamentar, os protagonistas do discurso - orador (deputado líder da minoria) e ouvinte (plenário da Câmara Federal) - estão colocados numa relação de assimetria, porque o partido do orador é minoria na composição da Câmara, e, consequentemente, numa relação de antagonismo, devido à filiação partidária e, logo, ao (não) alinhamento ao regime militar. Nesse processo de colocação dos protagonistas do discurso, é importante considerar o efeito de deslizamento de sentidos dos lugares do discurso político para os lugares do discurso judiciário que é produzido pela materialização do campo lexical do julgamento. Assim, ao observar a imagem do lugar do orador para o próprio orador (“Quem sou eu para lhe falar assim?”) e a imagem do lugar do

11 Na acepção de Authier-Revuz (1990; 2004). 
Linha D'Água (Online), São Paulo, v. 29, n. 2, p. 97-121, dez. 2016

plenário da Câmara para o orador ("Quem é ele para que eu lhe fale assim?"), a constituição do sujeito orador é atravessada pela imagem do advogado que enuncia num tom que lhe permite se aproximar do júri (o plenário da Câmara) para sensibilizá-lo, como o fazem os defensores, ao passo que a constituição dos sentidos do objeto do discurso desliza da "deliberação" política de afastar ou não um deputado para o "julgamento" de não apenas um deputado, mas de toda os deputados, ou seja, do valor de representatividade, de democracia.

Por meio de sequências de enunciados que valorizam o parecer do Ministro da Justiça e de itens lexicais "lição", "guia" e "orientação" e "orientar", o pronunciamento do parlamentar/“advogado" Mário Covas apresenta ao plenário da Câmara a imagem do Ministro da Justiça como um jurista que possui autoridade máxima sobre o assunto para, inclusive, enunciar no lugar do próprio orador o seguinte enunciado-sentença: "o abuso do direito político praticado, sem dúvida, pelo incontinente Deputado não atenta contra a ordem democrática” (DIÁRIO OFICIAL DA CÂMARA DOS DEPUTADOS, 2000, p. 103). Considerando o ponto de vista do orador sobre o objeto do discurso, isto é, a questão implícita "De que lhe falo assim?” (PÊCHEUX, 2001 [1969], p. 84), é importante notar como a construção da imagem do objeto do discurso também participa da constituição da própria imagem do orador.

Enfim, podemos concluir que, do ponto de vista da análise argumentativa, seria razoável dizer que o orador Mário Covas evoca, por meio dessa citação ao parecer do Ministro Gama e Silva, as vozes do establishment para amparar seu ponto de vista, o que consistiria num exemplo de estratégia argumentativa astuciosa, a saber: o orador integra favoravelmente ao seu discurso o argumento daquele que encaminhou o pedido para processar seu próprio colega de partido. Mas, do ponto de vista da análise discursiva, os efeitos de sentido de argumentação desse pronunciamento endereçado a uma frente ampla são complexos, pois tais efeitos constituem uma fissura no discurso oposicionista da formação discursiva do MDB, materializando não a ruptura com o regime, como no pronunciamento de defesa do próprio deputado Márcio Moreira Alves, mas a manutenção da subsistência clandestina da democracia no regime ditatorial. 
Linha D'Água (Online), São Paulo, v. 29, n. 2, p. 97-121, dez. 2016

\section{Considerações finais}

Chegando neste ponto do trabalho, podemos considerar que a tarefa de preencher a lacuna da dimensão ideológica da argumentação no discurso requer discussão e formulação teórica calcada no pluralismo epistemológico, pois se busca mais as proximidades do que os distanciamentos entre os estudos da argumentação e do discurso. Inspirados nesse ideário, pudemos argumentar de que maneira concebemos a argumentação como efeito de sentido entre os sujeitos do discurso, destacando a interdiscursividade e as formações imaginárias como conceitos centrais para a compreensão do mecanismo de argumentação no discurso, bem como observamos de que modo os trabalhos de Pêcheux, Fuchs e Orlandi, de um lado, e os de Plantin, Amossy e Maingueneau, de outro, inscrevem-se, distintamente, no longo processo de restauração do sujeito nos estudos da argumentação iniciado por Perelman, Olbrechts-Tyteca e Toulmin.

Quanto à nossa análise do pronunciamento parlamentar, esperamos ter mostrado que os resultados da análise da articulação das técnicas argumentativas podem ser bem mais profícuos e contextualizados se aliados à análise da dimensão ideológica do discurso. Para isso, reiteremos que, se a Análise do Discurso é uma das herdeiras da Retórica, ela se desenvolve como uma disciplina marcada pelas conquistas do nosso tempo, tais como as apontadas pelos mestres da suspeita: Marx, Nietzsche e Freud.

Por fim, é evidente que nosso trabalho empreendeu esforço para refletir acerca da argumentação sob uma única perspectiva de análise do discurso, a materialista, todavia sabemos e desejamos que outras tendências das teorias discursivas voltem sua atenção para a argumentação, sobretudo nestes tempos obscuros de convicções sem razões e de propostas de embotamento dos sujeitos em todos os níveis do ensino oficial no Brasil. 
Linha D'Água (Online), São Paulo, v. 29, n. 2, p. 97-121, dez. 2016

\section{Referências}

AMOSSY, Ruth. O lugar da argumentação na análise do discurso: abordagens e desafios contemporâneos. Tradução de Adriana Zavaglia. Filologia e linguistica portuguesa, São Paulo, n. 9, p. 121-146, 2007. Disponível em: 〈http://www.revistas.usp.br/flp/article/view/59776>.

Argumentação e Análise do Discurso: perspectivas teóricas e recortes disciplinares. Tradução de Eduardo Lopes Piris e Moisés Olímpio Ferreira. EIDËA - Revista Eletrônica de Estudos Integrados em Discurso e Argumentação, Ilhéus, n.1, p. 129-144, 2011. Disponível em: $<\mathrm{http}: / /$ www.uesc.br/revistas/eidea/revistas/revista1/eideaartigo12.pdf〉.

L'argumentation dans le discours. 3. ed. Paris: Armand Colin, 2013.

ARISTÓTELES. Retórica. Tradução de Manuel Alexandre Júnior, Paulo Farmhouse Alberto e Abel do Nascimento Pena. Lisboa: Imprensa Nacional - Casa da Moeda, 1998 [c. 330-326 a.C.].

AUTHIER-REVUZ, Jacqueline. Heterogeneidade(s) enunciativa(s). Tradução de Celene M. Cruz e João Wanderley Geraldi. Cadernos de Estudos Lingüísticos, Campinas, n. 19, p. 25-42, jul./dez.1990. Disponível em: <http://revistas.iel.unicamp.br/index.php/cel/article/ view/3012/4095>.

. Heterogeneidade mostrada e heterogeneidade constitutiva: elementos para uma abordagem do outro no discurso. In: Entre a transparência e a opacidade: um estudo enunciativo do sentido. Revisão da tradução de Leci Borges Barbisan et al. Porto Alegre: Edipucrs, 2004. p. 11-80.

COURTINE, Jean-Jacques. Análise do discurso político: o discurso comunista endereçado aos cristãos. Supervisão da tradução por Patrícia Chittoni Ramos Reuillard. São Carlos: EdUFSCar, 2009 [1981].

DIÁRIO OFICIAL DA CÂMARA DOS DEPUTADOS. Centro de publicações da Câmara dos Deputados. Brasília, Suplemento ao no 098, 1 jun. 2000. Disponível em: <http://imagem. camara.gov.br/Imagem/d/pdf/DCD01JUN2000SUP.pdf\#page=>. Acesso em: 29 ago.2016.

DUCROT, Oswald. A propos de la seconde Provinciale. Langue française, Paris, v.12, n.1 p. 9092, 1971. Disponível em : <http://www.persee.fr/doc/lfr_0023-8368_1971_num_12_1_5561>. 
Linha D'Água (Online), São Paulo, v. 29, n. 2, p. 97-121, dez. 2016

FUCHS, Catherine. As problemáticas enunciativas: esboço de uma apresentação histórico e crítica. Tradução de Letícia M. Rezende. Alfa, São Paulo, n. 29, p. 111-120, 1985. Disponível em: <http://seer.fclar.unesp.br/alfa/article/view/3759/3482>.

LE GUERN, Michel. Lethos dans la rhétorique française de l'âge classique. Stratégies discursives: Actes du colloque de Lyon (20-22 mai. 1977). Lyon: Presses Universitaires de Lyon, 1978. p. 281-287.

MAINGUENEAU, Dominique. Novas tendências em Análise do Discurso. Tradução de Freda Indursky. 3.ed. Campinas: Pontes, 1997 [1987].

. Argumentação e Análise do Discurso: reflexões a partir da segunda Provincial. [1994]. Tradução de Eduardo Lopes Piris e Moisés Olímpio Ferreira. In: BARONAS, Roberto Leiser; MIOTELLO, Valdemir (Org.). Análise de Discurso: teorizações e métodos. São Carlos: Pedro \& João Editores, 2011.p. 69-86.

MAZIÈRE, Francine. L'Analyse du discours: histoire et pratiques. Paris: PUF, 2005.

ORLANDI, Eni Puccinelli. Discurso e Argumentação: um observatório do político. Fórum Linguístico. Florianópolis, n.1, p. 73-81, jul-dez.1998. Disponível em: <https://periodicos.ufsc. br/index.php/forum/article/view/6915/6378>

. A linguagem e seu funcionamento: as formas do discurso. 6.ed. Campinas: Pontes Editores, 2011 [1983].

PÊCHEUX. Michel. Semântica e discurso: uma crítica à afirmação do óbvio. 3.ed. Tradução de Eni Puccinelli Orlandi et al. Campinas: Ed.UNICAMP, 1997 [1975].

Análise Automática do Discurso (AAD-69). Tradução de Eni P. Orlandi. In: GADET, Françoise; HAK, Tony (Org.). Por uma análise automática do discurso. 3.ed. 1.reimpr. Campinas: Ed.Unicamp, 2001 [1969]. p. 61-161.

; FUCHS, Catherine. A propósito da Análise Automática do Discurso: atualização e perspectivas (1975). [1975]. Tradução de Péricles Cunha. In: GADET, Françoise; HAK, Tony (Org.). Por uma análise automática do discurso. 3.ed. 1.reimpr. Campinas: Ed.Unicamp, 2001. p. 163-252. 
Linha D'Água (Online), São Paulo, v. 29, n. 2, p. 97-121, dez. 2016

PERELMAN, Chaïm; OLBRECHTS-TYTECA, Lucie. Tratado da Argumentação: a nova retórica. Tradução de Maria Ermantina Galvão G. Pereira. São Paulo: Martins Fontes, 1996 [1958].

PLANTIN, Christian. L'argumentation. Paris: Seuil, 1996.

A argumentação: história, teorias, perspectivas. Tradução de Marcos Marcionilo. São Paulo: Parábola, 2008 [2005].

PLEBE, Armando; EMANUELE, Pietro. Manual de Retórica. Tradução de Eduardo Brandão. São Paulo: Martins Fontes, 1992 [1988].

TOULMIN, Stephen. Os usos do argumento. 2.ed. Tradução de Reinaldo Guarany. São Paulo: Martins Fontes, 2006 [1958].

Recebido em: 29/08/2016. Aprovado em: 20/09/2016. 